\title{
PENGEMBANGAN PERANGKAT PEMBELAJARAN DENGAN MODEL EXPERIENTAL LEARNING PADA MATERI KUBUS DAN BALOK UNTUK SISWA KELAS VIII SMP
}

\author{
Anita Sari \\ Pendidikan Matematika, Universitas Riau \\ Email : anita.sari@student.unri.ac.id
}

\begin{abstract}
The background of this research is the limited of learning device as a means of supporting learning referring to 2013 curriculum. This research aims to develop syllabus, Learning Implementation Plan (LIP) and Student Learning Worksheet (SLW) with experiential learning model on the subject of cubes and beams for $8^{\text {th }}$ grade students of junior high school. The research used Research and Develomant (R\&D) with the ADDIE procedure; analyze, design, development, implementation, and evaluation. Due to time constraints, this research is only done until the development stage. This research instrument used are sheet of learning device validation, questionnaire response of learnears, and evaluation of learning outcomes. Syllabus, LIP and SLW validated two times by three validators and revised according to the suggestion from the validator. The valid LIP was then limited tested with the subject of nine students of $8^{\text {th }}$ grade in SMP Muhammadiyah 1 Pekanbaru. Based on the analysis result of the validation data, it can be concluded that syllabus and LIP are considered very valid and SLW is valid with average rating for syllabus is 3.44, LIP is 3.34 and SLW is 3.13. In the second validation, it can be concluded that the syllabus, LIP and SLW are considered very valid with the average rating for the syllabus is 3.75, for the LIP is 3.65 and for SLW is 3.47. Based on the analysis results of the questionnaire response of learners to $S L W$ in the limited trial is $95.5 \%$ with very practical category and the average of the result of student's evaluation is 84.8. Based on the results of data analysis and discussion concluded that the syllabus, LIP, and SLW with experiential learning model on the subject of cubes and beams for $8^{\text {th }}$ grade students of Junior High School have fulfilled the validity and practical requirements to used by $8^{\text {th }}$ grade students of Junior High School.
\end{abstract}

Keywords : Experiential learning model, Learning device, Cubes and beams, Validity and practicality

\section{PENDAHULUAN}

Pendidikan merupakan salah satu faktor penentu kualitas dan kemajuan suatu bangsa. Oleh karena itu, pemerintah melalui Kemendikbud terus berusaha mengupayakan perbaikan dan pembaharuan pendidikan, salah satunya dengan memberlakukan kurikulum 2013. Pembelajaran pada Kurikulum 2013 menuntut siswa untuk aktif mengkonstruksi pengetahuannya sendiri melalui aktivitas belajar. Kegiatan pembelajaran tentunya harus didukung dengan perangkat pembelajaran. Perangkat pembelajaran Kurikulum 2013 yang sudah disediakan pemerintah adalah silabus, sedangkan RPP dan LKS yang mengacu pada Kurikulum 2013 harus dibuat oleh guru sesuai dengan kebutuhan siswa.

Berdasarkan observasi yang dilakukan peneliti di SMP Muhammadiyah 1 Pekanbaru dan SMP Negeri 8 Pekanbaru, silabus yang digunakan guru merupakan silabus yang diterbitkan oleh Kemendikbud yang merupakan desain minimal, tanpa mempertimbangkan kebutuhan siswa di sekolah. RPP yang disusun guru masih mengacu pada Permendikbud No. 103 Tahun 2014. Guru masih mencantumkan penilaian sikap pada RPP yang digunakannya. Guru juga menyatakan bahwa dalam membuat perangkat pembelajaran guru lebih banyak mencari dari internet dan memodifikasi seperlunya saja hanya untuk memenuhi syarat laporan yang harus diserahkan kepada pihak sekolah di awal semester.

Proses pembelajaran yang dilakukan guru matematika SMP Muhammadiyah 1 Pekanbaru adalah menjelaskan materi pelajaran, memberikan contoh-contoh soal, dan kemudian memberikan latihan. Sumber belajar yang digunakan oleh guru hanya buku matematika dari penerbit. Untuk menyediakan LKS setiap pertemuan, guru terkendala waktu dalam membuatnya. Hal ini tidak sesuai dengan Kurikulum 2013 yang mengisyaratkan pembelajaran yang dikehendaki adalah pembelajaran yang mengedepankan pengalaman personal melalui kegiatan saintifik. Permasalahan yang ditemukan memerlukan solusi yaitu perlunya pengembangan perangkat 
pembelajaran yang sesuai dengan tuntutan kurikulun.

Perangkat pembelajaran yang dikembangkan mengacu pada tuntutan Kurikulum 2013 dan memenuhi kriteria valid serta praktis. Validitas perangkat pembelajaran adalah suatu tindakan yang dilakukan oleh pakar di bidangnya (validator) untuk memberikan status valid atau sah, yang ditentukan dari rata-rata nilai yang diberikan oleh validator pada perangkat pembelajaran. Praktikalitas adalah suatu tindakan untuk mengukur tingkat ketercapaian keterlaksanaan perangkat pembelajaran.

Silabus merupakan acuan bagi guru dalam merancang dan melaksanakan kegiatan pembelajaran. Penyusunan silabus ini dilakukan dengan prinsip keselarasan antara ide, desain, dan pelaksanaan kurikulum. Silabus disusun untuk mempermudah dalam pengembangan RPP. RPP adalah rencana kegiatan pembelajaran tatap muka untuk satu pertemuan atau lebih yang salah satu komponennya adalah langkah-langkah pembelajaran. Langkah pembelajaran berkaitan erat dengan model pembelajaran yang dipilih karena model pembelajaran menggambarkan kegiatan pembelajaran yang terjadi di kelas untuk mencapai tujuan pembelajaran.

Tujuan pembelajaran dapat tercapai apabila guru memberikan kesempatan kepada siswa untuk berperan aktif dalam setiap pembelajaran yang dilakukan. Salah satu alternatif yang dapat dilakukan guru agar siswa dapat berperan aktif dan mandiri untuk mengembangkan pengetahuannya adalah dengan menggunakan Lembar Kerja Siswa (LKS). LKS menyajikan materi secara ringkas dan sistematis, sehingga siswa dapat dengan mudah mengonstruksi informasi-informasi yang disampaikan. LKS dapat digunakan siswa untuk menemukan suatu konsep secara mandiri dengan memecahkan setiap masalah yang ada di dalamnya. LKS juga menyediakan soal yang beragam sehingga dapat meningkatkan pengalaman siswa untuk menyelesaikan berbagai persoalan yang berhubungan dengan kehidupan sehari-hari (Nugroho, 2015).

Berdasarkan hasil penelitiannya, Dyahsih dan Ali (2015) menyimpulkan bahwa model pembelajaran yang memungkinkan siswa untuk berpartisiasi aktif dalam belajar adalah model experiential learning, namun ketika guru menerapkan model experiential learning hendaknya menyiapkan segala perangkat pembelajaran yang dibutuhkan. Menurut Maat, dkk. (2017) pembelajaran matematika dengan model experiential learning atau pembelajaran berasaskan pengalaman di Sekolah Menengah Pertama (SMP) di kota Pekanbaru tidak terlaksana karena kurangnya kemahiran guru dalam mencari ide-ide pengalaman konkrit yang dijalankan siswa, kurangnya media dan alat bantu pembelajaran, waktu pelajaran yang terbatas dan biaya yang relatif tinggi. Experiential Learning merupakan proses belajar, proses perubahan yang menggunakan pengalaman sebagai media belajar atau pembelajaran (Kolb dalam Prasetyo, 2011). Oleh karena itu, experiential learning dapat digunakan sebagai salah satu model yang mengedepankan pengalaman.

Experiential learning memiliki empat tahap pembelajaran yaitu Concrete Experience (CE)/Pengalaman Konkret, Reflective Observation (RO)/Observasi, Abstract Conceptualization (AC)/ Konseptualisasi Abstrak, Active Experimentation (AE)/Percobaan. Materi matematika yang sesuai dengan model experiential learning adalah geometri. Materi geometri yang diajarkan pada siswa kelas VIII diantaranya adalah kubus dan balok. Experiential learning merupakan salah satu model pembelajaran yang cocok untuk mengajarkan materi kubus dan balok, karena aplikasi bentuk dari bangun ruang kubus dan balok banyak dijumpai dalam kehidupan sehari-hari, sehingga memudahkan siswa mendapatkan pengalaman langsung.

Dengan demikian, peneliti termotivasi untuk mengembangkan perangkat pembelajaran dengan model experiential learning pada materi kubus dan balok di kelas VIII SMP agar dapat menjadi referensi bagi guru untuk melaksanakan pembelajaran dengan mengedepankan pengalaman siswa secara langsung.

\section{METODE}

Penelitian ini adalah penelitian pengembangan (research and development). Produk yang dihasilkan dari penelitian ini adalah perangkat pembelajaran berupa silabus, Rencana Pelaksanaan Pembelajaran (RPP) dan Lembar Kerja Siswa (LKS) dengan model experiential learning pada materi kubus dan 
balok kelas VIII SMP. Model pengembangan yang digunakan adalah ADDIE. Langkahlangkah yang dikembangkan terdiri dari tiga tahap yaitu analyze (analisis), design (perancangan) dan development (pengembangan).

Subjek penelitian pada uji coba terbatas adalah sembilan siswa kelas VIII-2 SMP Muhammadiyah 1 Pekanbaru dengan kemampuan akademis yang heterogen. Instrumen pengumpul data pada penelitian ini adalah lembar validasi dan angket respon siswa. Lembar validasi dan angket respon siswa menggunakan angket tertutup dan terbuka. Angket tertutup digunakan untuk mendapatkan skor penilaian dan angket terbuka digunakan untuk mendapatkan komentar dan saran perbaikan. Dalam mengisi angket validasi tertutup terdiri dari empat alternatif jawaban, yaitu 1, 2, 3, dan 4 yang masing-masin menyatakan sangat baik, baik, kurang baik, dan tidak baik. Sedangkan dalam mengisi angket respon siswa terbuka terdiri dari dua alternatif jawaban, yaitu ya dan tidak yang masingmasing memiliki skor 1 dan 0 .

Teknik analisis data pada penelitian ini terdiri dari analisis lembar validasi dan analisis angket respon siswa. Analisis lembar validasi silabus, RPP dan LKS menggunakan rumus berikut.

$$
\bar{M}_{v}=\frac{\sum_{i=1}^{n} \bar{V}_{i}}{n}
$$

Keterangan:

$\bar{M}_{v}$ : rata-rata total validasi

$\bar{V}_{i}$ : rata-rata validasi validator ke- $i$

$n$ : banyaknya validator

Adapun kriteria validasi analisis rata-rata yang digunakan dapat dilihat pada Tabel 1 .

Tabel 1. Kategori Validitas perangkat Pembelajaran

\begin{tabular}{cc}
\hline Interval & Kategori \\
\hline $\mathbf{3 , 2 5} \leq \overline{\boldsymbol{x}}<\mathbf{4}$ & Sangat Valid \\
$\mathbf{2 , 5 0} \leq \overline{\boldsymbol{x}}<\mathbf{3 , 2 5}$ & Valid \\
$\mathbf{1 , 7 5} \leq \overline{\boldsymbol{x}}<\mathbf{2 , 5 0}$ & Kuang Valid \\
$\mathbf{1 , 0 0} \leq \overline{\boldsymbol{x}}<\mathbf{1 , 7 5}$ & Tidak Valid \\
\hline
\end{tabular}

Sumber: Sugiyono (2012)

Data angket respon siswa dianalisis menggunakan rumus yang diadaptasi dari Akbar (2013) sebagai berikut:

$$
V_{p}=\frac{T_{s e}}{T_{s h}} \times 100 \%
$$

Keterangan:

$V_{p} \quad$ : skor responden

$T_{s p}$ : total skor empiris dari responden

$T_{s h}$ : total skor maksimal yang diharapkan

Adapun kriteria persentase keterbacaan dan keterlaksanaan LKS dapat dilihat pada Tabel 2.

Tabel 2. Kriteria Persentase Keterbacaan dan Keterlaksanaan LKS

\begin{tabular}{cc}
\hline Interval & Kriteria \\
\hline $\mathbf{8 5 , 0 1} \% \leq \boldsymbol{x}<\mathbf{1 0 0} \%$ & Sangat Praktis \\
$\mathbf{7 0 , 0 1} \% \leq \boldsymbol{x}<\mathbf{8 5 , 0 0} \%$ & Praktis \\
$\mathbf{5 0 , 0 1} \% \leq \boldsymbol{x}<\mathbf{7 0 , 0 0} \%$ & Kurang Praktis \\
$\mathbf{0 1}, \mathbf{0 0} \% \leq \boldsymbol{x}<\mathbf{5 0 , 0 0} \%$ & Tidak Praktis \\
\hline
\end{tabular}

Sumber: Akbar (2013)

\section{HASIL DAN PEMBAHASAN}

Tahap Analyze (Analisis)

Tahap analyze terdiri dari dua langkah yaitu melakukan analisis keperluan dan melakukan analisis kurikulum. Analisis keperluan yang dilakukan peneliti adalah untuk mengetahui karakteristik siswa. Hasil analisis karakteritik siswa didapatkan bahwa siswa kelas VIII pada umumnya berusia 13-14 tahun. Menurut Suwangsih, (2006) siswa SMP masih ada pada tahap operasi konkret, artinya jika ia akan memahami konsep abstrak matematika harus dibantu dengan menggunakan benda kongkrit. Salah satu model pembelajaran yang dapat membantu siswa dalam berpikir abstrak dan mementingkan pemahaman terhadap proses terbentuknya konsep menurut Munif dan Mosik (2009) adalah model pembelajaran experiential learning karena alur tahapan membelajaran model experiential learning dapat membantu siswa dalam berpikir abstrak dan sangat mendukung dalam peningkatan hasil belajar siswa.

Pada analisis kurikulum 2013 didapatkan Kompetensi Dasar (KD) yang terkait materi kubus dan balok adalah 3.9 Membedakan dan menentukan luas permukaan dan volume bangun ruang sisi datar (kubus, balok, prisma dan limas) dan 4.9 Menyelesaikan masalah yang berkaitan dengan luas permukaan dan volume bangun ruang sisi datar (kubus, balok, prisma dan limas), serta gabungannya. Materi pokok/pembelajaran dan alokasi waktu penelitian ini adalah luas permukaan kubus (2 JP), luas permukaan balok (3JP), volume kubus (2 JP) dan volume balok (3 JP). Kegiatan 
pembelajaran yang dilakukan siswa pada penelitian ini sesuai dengan model experiential learning dan pendekatan saintifik. Penilaian pencapaian KD pengetahuan dan keterampilan pada penelitian dilakukan dengan teknik tes tertulis dalam bentuk uraian penyelesaian masalah. Selanjutnya penentuan indikator pencapaian kompetensi dan tujuan pembelajaran sesuai dengan tuntutan $\mathrm{KD}$.

\section{Tahap Design (Perancangan)}

Kegiatan yang dilakukan peneliti pada tahap design adalah membuat rancangan perangkat pembelajaran, merancang lembar validasi perangkat pembelajaran dan merancang angket respon siswa terhadap keterlaksanaan penggunaan LKS. Dalam merancang kegiatan pembelajaran, peneliti merancang komponenkomponen yang terdapat pada silabus, RPP dan LKS. Pada lembar validasi dan angket respon siswa, peneliti mengembangkan aspek yang dinilai yang memiliki beberapa indikator dan butir penilaian.

Komponen-kompenen silabus yang dikembangkan mengacu kepada Permendikbud No. 22 Tahun 2016, serta Wardhani dan Herawati (2009) yaitu terdiri dari (1) identitas mata pelajaran; (2) identitas sekolah; (3) kompetensi inti; (4) kompetensi dasar; (5) materi pokok atau pembelajaran; (6) kegiatan pembelajaran; (7) indikator pencapaian kompetensi; (8) penilaian; (9) alokasi waktu; dan (10) sumber belajar.

Komponen-kompenen RPP yang dikembangkan mengacu kepada perpaduan Permendikbud No. 103 Tahun 2014 dan Permendikbud No. 22 Tahun 2016, serta Wardhani dan Herawati (2009), yaitu terdiri dari: (1) identitas sekolah; (2) identitas mata pelajaran; (3) kelas/semester; (4) materi pokok (5) materi pembelajaran; (6) alokasi waktu; (7) Kompetensi Inti (KI); (8) Kompetensi Dasar (KD) dan indikator pencapaian kompetensi; (9) tujuan pembelajaran; (10) deskripsi materi pembelajaran; (11) pendekatan/model/metode pembelajaran; (12) media/alat/dan bahan pembelajaran; (13) sumber belajar; (14) langkah-langkah pembelajaran; (11) penilaian proses dan hasil pembelajaran.

Pada halaman depan LKS terdiri dari judul materi pembelajaran, identitas siswa, waktu, gambar pendukung, tujuan pembelajaran dan petunjuk. Bagian isi LKS yang dikembangkan sesuai dengan kebutuhan materi dan model experiental learning pada pendekatan saintifik yang digunakan.

Lembar validasi silabus dibuat untuk menilai beberapa aspek, yaitu: (1) identitas; (2) pemilihan kegiatan pembelajaran; (3) penilaian hasil belajar, yang memiliki indikator penilaian kesesuaian teknik penilaian dengan pendekatan saintifik; (4) penentuan alokasi waktu; dan (5) pemilihan sumber belajar. Lembar validasi RPP dirancang berdasarkan beberapa aspek, yaitu: (1) identitas; (2) pemilihan materi; (3) perumusan kegiatan pembelajaran; pemilihan media, alat, dan sumber belajar; serta (5) penilaian hasil belajar. Lembar validasi LKS dirancang berdasarkan beberapa aspek, yaitu: (1) kualitas materi, (2) kesesuaian penyajian LKS dengan model experiential learning; (3) kesesuaian LKS dengan syarat didaktis; (4) kesesuaian LKS dengan syarat konstruksi (kebahasaan); dan (5) kesesuaian LKS dengan syarat teknis. Sedangkan angket respon siswa dirancang berdasarkan beberapa aspek, yaitu: (1) materi; (2) tampilan; (3) kemudahan penggunaan LKS; (4) permasalahan berbasis pengalaman; dan (5) sikap belajar siswa.

\section{Tahap Development (Pengembangan)}

Pada tahap ini dilakukan dua kegiatan yaitu pengembangan silabus, RPP, dan LKS serta evaluasi formatif terhadap pengembangan silabus, RPP dan LKS yang meliputi kegiatan validasi, revisi perangkat pembelajaran, dan uji coba terbatas. Pada tahap pengembangan silabus, RPP, dan LKS, peneliti membuat perangkat pembelajaran sesuai dengan rancanagan. Perangkat yang dikembangkan terlebih dahulu adalah silabus kemudian RPP. Kegiatan pembelajaran pada silabus dan RPP disesuaikan dengan model experiential learning dan pendekatan saintifik. Kemudian peneliti mengembangkan LKS dengan menerapkan langkah-langkah pada model experiential learning dan pendekatan saintifik untuk materi kubus dan balok kelas VIII SMP. Kegiatan yang terdapat di LKS dibuat agar siswa termotivasi untuk menemukan rumus melalui pengalaman langsung dan menerapkan konsep matematika untuk menyelesaikan permasalahan yang ada. Desain LKS dibuat menarik secara visual agar siswa bersemangat dalam mengikuti kegiatan pembelajaran. 
Silabus, RPP, dan LKS yang telah dikembangkan kemudian divalidasi sebanyak dua kali oleh validator. Pada validasi pertama validator memberikan saran dan komentar perbaikan. Adapun saran validator pada validasi pertama disajikan pada Tabel 3 .

Tabel 3. Saran Validator pada Validasi Pertama

\begin{tabular}{|c|c|}
\hline $\begin{array}{c}\text { Perangkat } \\
\text { Pembelajaran }\end{array}$ & Saran Validator \\
\hline Silabus & $\begin{array}{l}\text { 1) Pada aspek penilaian } \\
\text { pengetahuan bahwa tes } \\
\text { lisan tidak diberikan } \\
\text { kepada siswa, penugasan } \\
\text { LKS tidak untuk menilai } \\
\text { hasil belajar, dan pada } \\
\text { aspek penilaian } \\
\text { keterampilan diganti } \\
\text { dengan teknik tes tertulis. } \\
\text { 2) Perlu ditambahkan alat } \\
\text { peraga yang digunakan. }\end{array}$ \\
\hline$\overline{\mathrm{RPP}}$ & $\begin{array}{l}\text { 1) Perhatikan alokasi waktu } \\
2 \times 40 \text { menit tetapi sebaran } \\
\text { waktu pada kegiatan } \\
\text { pembelajaran menjadi } \\
\pm 90 \text { menit. } \\
\text { 2) Sesuaikan kembali } \\
\text { indikator pencapaian } \\
\text { kompetensi. } \\
\text { 3) Sesuaikan kembali tujuan } \\
\text { pembelajaran. } \\
\text { 4) Periksa kembali } \\
\text { pengertian balok. } \\
\text { 5) Periksa kembali } \\
\text { penurunan rumus } \\
\text { 6) Kegiatan menanya kurang } \\
\text { sesuai } \\
\text { 7) Pisahkan soal } \\
\text { pengetahuan dan } \\
\text { keterampilan } \\
\text { 8) Rubrik penilaian } \\
\text { instrumen perlu } \\
\text { disesuaikan dengan } \\
\text { langkah penyelesaian } \\
\text { masalah }\end{array}$ \\
\hline LKS & $\begin{array}{l}\text { 1) Cover LKS terlalu ramai } \\
\text { 2) Pada concrete experience } \\
\text { gunakan gambar yang } \\
\text { dekat dengan siswa dan } \\
\text { beri wacana } \\
\text { 3) Gambar kubus utama } \\
\text { perlu diperbaiki warnanya } \\
\text { sehingga terang dan jelas }\end{array}$ \\
\hline
\end{tabular}

4) Perhatikan kembali tulisan karena ada beberapa tulisan yang terpotong gambar

5) Warna tulisan pada tahapan experiential learning ganti dengan warna putih

6) Warna biru pada page number terlalu pekat sehingga tulisan tidak terlihat jelas

7) Perlu diperhatikan lagi kalimat pada kegiatan ayo menalar

8) Kalimat pada soal latihan perlu diperjelas lagi

Silabus, RPP, dan LKS pada validasi pertama direvisi sesuai dengan saran validator sebelum dilakukan validasi kedua. Hasil penilaian validator terhadap silabus, RPP, dan LKS dengan model experiential learning pada materi kubus dan balok kelas VIII SMP, pada validasi kedua dapat dilihat pada Tabel 4.

Tabel 4. Rata-rata Nilai Validasi Silabus, RPP, dan LKS

\begin{tabular}{ccc}
\hline $\begin{array}{c}\text { Perangkat } \\
\text { Pembelajaran }\end{array}$ & Rata-rata & $\begin{array}{c}\text { Kategori } \\
\text { Validasi }\end{array}$ \\
\hline Silabus & 3,75 & Sangat Valid \\
RPP & 3,65 & Sangat Valid \\
LKS & 3,47 & Sangat Valid \\
\hline
\end{tabular}

Pada validasi kedua, validator tidak memberikan saran dan komentar perbaikan namun memberi kesimpulan bahwa perangkat yang dikembangkan layak uji coba tanpa revisi dengan rata-rata nlai untuk silabus adalah 3,75, RPP adalah 3,65, dan LKS adalah 3,47. Silabus, RPP, dan LKS mendapatkan kategori validasi sangat valid.

Setelah silabus, RPP dan LKS dikatakan valid dan layak uji coba tanpa revisi, selanjutnya peneliti melakukan uji coba terbatas. Subjek penelitian pada uji coba terbatas adalah sembilan siswa kelas VIII-2 SMP Muhammadiyah 1 Pekanbaru dengan kemampuan akademis yang heterogen. Pada uji coba ini siswa diminta untuk melakukan dan menyelesaikan kegiatan-kegiatan yang termuat pada LKS. Setelah siswa selesai mengerjakan LKS, peneliti membagikan angket respon dan meminta siswa untuk mengisi angket. 
Persentase respon siswa terhadap kepraktisan LKS pada uji coba terbatas dapat dilihat pada Tabel 5.

Tabel 5. Persentase Respon Siswa terhadap Kepraktisan LKS pada Uji Coba Terbatas

\begin{tabular}{|c|c|c|c|c|c|c|}
\hline \multirow{2}{*}{$\begin{array}{c}\text { Perangkat } \\
\text { Pembelajar } \\
\text { an }\end{array}$} & \multicolumn{4}{|c|}{$\begin{array}{l}\text { Pertemuan ke- } \\
(\%)\end{array}$} & \multirow{2}{*}{$\begin{array}{l}\text { Rat } \\
\text { a- } \\
\text { rata }\end{array}$} & \multirow{2}{*}{$\begin{array}{c}\text { Kateg } \\
\text { ori }\end{array}$} \\
\hline & 1 & 2 & 3 & 4 & & \\
\hline \multirow{2}{*}{ LKS } & 9 & 9 & 9 & 9 & 95 & Sangat \\
\hline & 7 & 3 & 5 & 7 & 5 & Praktis \\
\hline
\end{tabular}

Peneliti melakukan analisis berdasarkan hasil uji coba terbatas dan ditemukan bahwa terdapat beberapa siswa tidak menuliskan apa yang diketahui dan ditanya pada saat menyelesaikan soal, dan ukuran kolom simpulan yang terlalu besar sehingga peneliti melakukan revisi. Pada kolom jawaban, peneliti menambahkan perintah untuk menuliskan apa yang diketahui dan ditanya pada soal. Pada kolom kesimpulan peneliti memperkecil ukuran kolom.

Setelah tahap uji coba selesai, peneliti melakukan penilaian hasil belajar pada materi kubus dan balok. Nilai yang diperoleh siswa dalam menyelesaikan soal-soal dapat dilihat pada Tabel 6.

Tabel 6. Penilaian Hasil Belajar Siswa

\begin{tabular}{cc}
\hline Siswa ke- & Nilai \\
\hline 1 & 79,3 \\
2 & 84,5 \\
3 & 77,6 \\
4 & 91,4 \\
5 & 86,2 \\
6 & 98,3 \\
7 & 84,5 \\
8 & 84,5 \\
9 & 84,5 \\
\hline Rata-Rata & 84,8 \\
\hline
\end{tabular}

Dari penilaian hasil belajar dapat dilihat bahwa nilai setiap siswa maupun nilai rata-rata siswa telah lebih besar dari nilai KKM yang ditetapkan oleh sekolah yaitu 75 . Hal ini berarti bahwa pembelajaran menggunakan LKS dengan model experiential learning telah tercapai pada materi kubus dan balok.

\section{SIMPULAN}

Silabus, RPP, dan LKS dengan model experiential learning pada materi kubus dan balok kelas VIII yang dihasilkan telah melewati setiap tahap pengembangan model ADDIE sampai tahapan development (pengembangan). Seluruh validator telah memberikan penilaian terhadap setiap aspek pada instrumen perangkat pembelajaran. Dari hasil validasi dan uji coba, diperoleh bahwa pengembangan silabus, RPP dan LKS dengan model experiential learning pada materi kubus dan balok sudah memenuhi aspek valid dan syarat praktikalitas untuk digunakan di SMP.

\section{REKOMENDASI}

Beberapa saran yang dapat peneliti berikan sehubungan dengan penelitian dalam rangka pengembangan perangkat pembelajaran adalah sebagai berikut.

1. Direkomendasikan agar mengembangkan perangkat pembelajaran dengan model experiential learning untuk materi lainnya.

2. Pada penelitian pengembangan ini, peneliti hanya melaksanakan uji coba terbatas. Peneliti tidak melaksanakan uji coba kelompok besar karena waktu penelitian yang tidak sesuai dengan jadwal materi pelajaran. Peneliti menyarankan agar perangkat pembelajaran yang telah diuji cobakan secara terbatas dapat dilanjutkan untuk uji coba dalam kelompok besar.

\section{DAFTAR PUSTAKA}

Akbar, S. (2013). Instrumen Perangkat Pembelajaran. Bandung: Rosdakarya.

Dyahsih, A.S. dan Ali, M. (2015). Keefektifan Experiential Learning Pembelajaran Matematika MTs Materi Bangun Ruang Sisi Datar. Jurnal Riset Pendidikan Matematika, 2(2), 175-185.

Kemendikbud. (2014). Salinan Lampiran Permendikbud Nomor 103 tentang Pembelajaran pada Pendidikan Dasar dan Menengah. Jakarta: Kemendikbud.

Kemendikbud. (2016). Salinan Lampiran Permendikbud Nomor 22 tentang Standar Proses Pendidikan Dasar dan Menengah. Jakarta: Kemendikbud.

Maat, S.M., Suanto, E., dan Zakaria, E. (2017). Penerapan Pembelajaran Pengalaman dalam Pendidikan Matematika: Sebuah Kajian Awal. Seminar Pendidikan 
PRINSIP Pendidikan Matematika

Volume 1, Nomor 2, Mei 2019

Serantau ke VIII 2017 di UKM Malaysia, 1, 210-217.

Munif, I.R.S., dan Mosik. (2009). Penerapan Model Experiential Learning pada Pembelajaran IPA untuk Meningkatkan Hasil Belajar Sekolah Dasar. Jurnal Pendidikan Fisika Indonesia, 5,79-82.

Nugroho, N.B. (2015). Pengembangan RPP dan LKS Berbasis Problem Based Learning pada Materi Himpunan untuk Siswa SMP Kelas VII. E-Journal Universitas Negeri Yogyakarta, 1(1), 96-118.

Prasetyo, I. (2011). Telaah Teoretis Model Experiental Learning dalam Pelatihan Kewirausahaan Program Pendidikan Non Formal. Majalah Ilmiah Pembelajaran, 2(7), 103-119.
Sugiyono. (2012). Metode Penelitian Kuantitatif, Kualitatif, dan $R \& D$. Bandung: Alfabeta.

Suwangsih, E. (2006). Aliran Psikologi Kognitif. Bandung: Universitas Pendidikan Indonesia.

Wardhani, S., dan Herawati, R. (2009). Teknik Pengembangan Silabus dan RPP Matematika SMP. Sleman: PPPPTK Matematika. 